\title{
17
}

\section{Hydraulic Changes to Stormwater Flow Through Wetlands}

\author{
David A. Stern
}

Wetlands have been increasingly identified as important in ameliorating the impacts of stormwater flow. Key to understanding the attributes of wetlands is determining the behaviour of flow through wetlands. This report presents the average flow velocities for two wetland types (scrub-shrub and emergent) found within a natural wetland through the use of dye tracer tests. The study area was divided into wetland segments using the US Fish and Wildlife Service's National Wetland Inventory (NWI) classification scheme and mapped using a Global Positioning System (GPS). During different flow levels, dye was pumped into the headwaters of the wetland. The dye was collected with auto- samplers at several sampling stations located at the transition zones between wetland segments. Results indicate that there is a significant difference in the flow characteristics between scrub-shrub and emergent wetland types. Differences were also found between leaf-on and leaf-off seasons. High data variability was found for samples collected furthest from the dye injection point. The range of velocities observed for scrub-shrub classified segment during the leaf-on season was from 1.11 to $23.08 \mathrm{~m} / \mathrm{min}$. For the emergent classified segment, the range of velocities was from 1.54 to $7.68 \mathrm{~m} / \mathrm{min}$. Differences in the velocities between the two types of wetlands could be attributed to the sinuosity of the stream channels and the vegetation in the floodplain that is associated with each type of

Stern, D.A. 2006. "Hydraulic Changes to Stormwater Flow Through Wetlands." Journal of Water Management Modeling R225-17. doi: 10.14796/JWMM.R225-17.

(C) CHI 2006 www.chijournal.org ISSN: 2292-6062 (Formerly in Intelligent Modeling of Urban Water Systems. ISBN: 0-9736716-2-9) 
wetland. The range of velocities observed for scrub-shrub classified segment during the leaf-off season was from 0.45 to $11.31 \mathrm{~m} / \mathrm{min}$. For the emergent classified segment, the range of velocities was from 0.39 to 7.64 $\mathrm{m} / \mathrm{min}$. Differences in the velocities between seasons could be attributed to the amount and type of leaf litter found in the floodplain zones of the wetland. Currently, these results are being evaluated at a different wetland system to verify the findings. Improving our understanding of flow behavior of wetlands will lead to improved design parameters for natural wetland restoration. The findings from this study have also been used to develop a model to simulate flow through a naturally occurring wetland.

\subsection{Introduction}

Perhaps the most important natural feature of a watershed with regard to moderating the effects of stormwater flow are wetlands. Wetlands may remove up to $90 \%$ of the total suspended solids portion of turbidity (Schueler, 1992). In addition to pollution reduction, wetlands provide flood protection, critical habitats and buffers between urbanized and natural areas. However, research on the potential value of wetlands as natural filters is still in the early stages. Research directed at determining the attenuation of pollutants by wetlands has $\mathrm{f}$ ocused on sediment, nutrients (particularly nitrogen and phosphorus), pathogens, heavy metals and trace organic compounds. Much of the data collected has been from wetlands that were constructed for the primary purpose of treating municipal wastewater. Similarly, natural wetlands are expected to yield equivalent pollution reduction and have done so when such data have been collected (US EPA 1985). Accordingly, there is a large need to study the hydraulics of natural wetlands in further detail.

The most important parameter influencing the effectiveness of wetlands in retarding and removing pollutants is the hydrology of the wetland (Stern et al 2001; Mitsch 1993). The cumulative effect of wetlands on a watershed can result in the removal of between 23 and $93 \%$ of the sediment found in the watersheds' streams (Johnston et al 1990). Wetlands continually settle suspended solids although the rate of sedimentation may vary between wetlands and over time. Sedimentation is primarily enhanced due to the reduced stream velocity through wetlands. The ability of wetlands to improve water quality is derived from the following fundamental processes that occur in wetlands (US EPA 1985; Elder 1987): 
1. the low slope, low velocity and long retention time physically trap and settle pollutants suspended in the wetland influent;

2. the high sorptive capacity of wetland sediments entrap pollutants;

3. the diverse microbial community in both anaerobic and aerobic conditions of the sediment allow for significant biotransformation and utilization of influent pollutants; and

4. the high productivity biomass ratio of wetland vegetation consumes significant amounts of nutrients that may be present in the influent.

Each of these processes is related to the hydraulic characteristics of the wetland.

Not surprisingly, much of the literature on the hydraulics of wetlands relates to constructed wetlands. These wetland systems tend to have well defined and regular geometric shapes and are designed to maximize retention. Many naturally occurring wetlands differ from constructed wetlands by the presence of a channelized flow route which is seen as a shallow stream running through the wetland. The flow characteristics of this stream channel and the variable resistance associated with the vegetated segments of the wetland are difficult to measure directly. Accordingly, dye tracer tests are used since these provide the most convenient and accurate method to measure velocities of such conditions (Stern et al 1998; Kadlec and Knight 1996; Kadlec 2003).

The focus of this chapter is to provide a more detailed description of the flow through wetlands. Such a description can improve our understanding of how stormwater flows are changed not only by vegetation but also by the orientation of the stream components of a natural wetland.

\subsection{Description of the Study Area}

The area studied is situated within the Malcolm Brook watershed, which is located in a northern suburb of New York City in the Village of Valhalla, Westchester County, New York (Figure 17.1). The watershed is 0.36 square kilometers in size, with slopes ranging from 1 to $25 \%$, and with land uses that include commercial, residential and forest. Malcolm Brook drains into Kensico Reservoir, which is the source water reservoir for approximately $90 \%$ of the New York City water supply. 


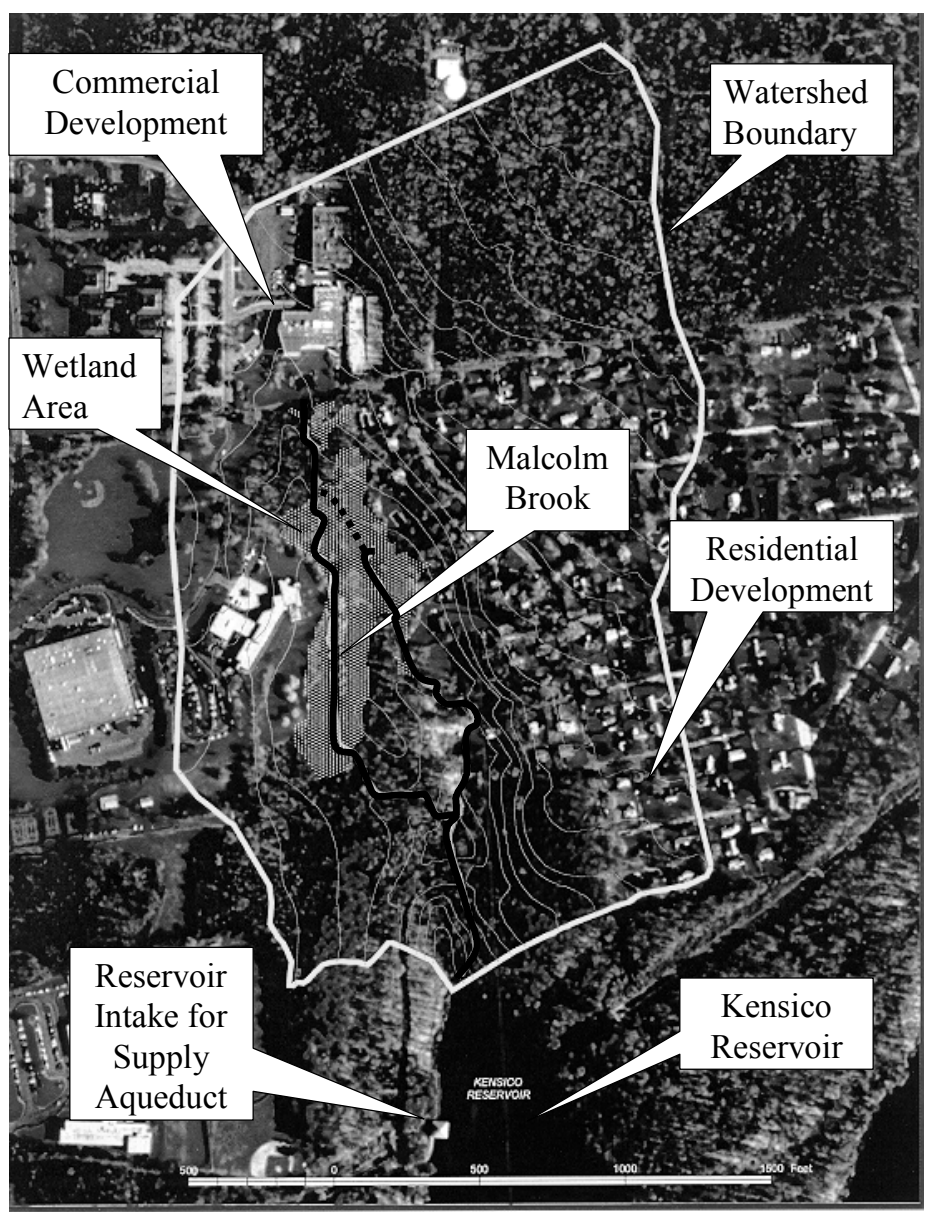

Figure 17.1 Malcolm Brook watershed.

The watershed flows in a north-to-south orientation. The headwaters of the Malcolm Brook begin with the drainage from a commercial office development. Approximately $100 \mathrm{~m}$ south of this development, the stream bifurcates. The eastern branch flows through a channelized and suburbanized area. The western branch travels through scrub-shrub, emergent and mixed (scrub-shrub and emergent) wetlands, empties into a shallow pond and then flows in its southern reach through a steep channel. The channels rejoin just north of West Lake Drive and flow approximately $200 \mathrm{~m}$ to the reservoir. 


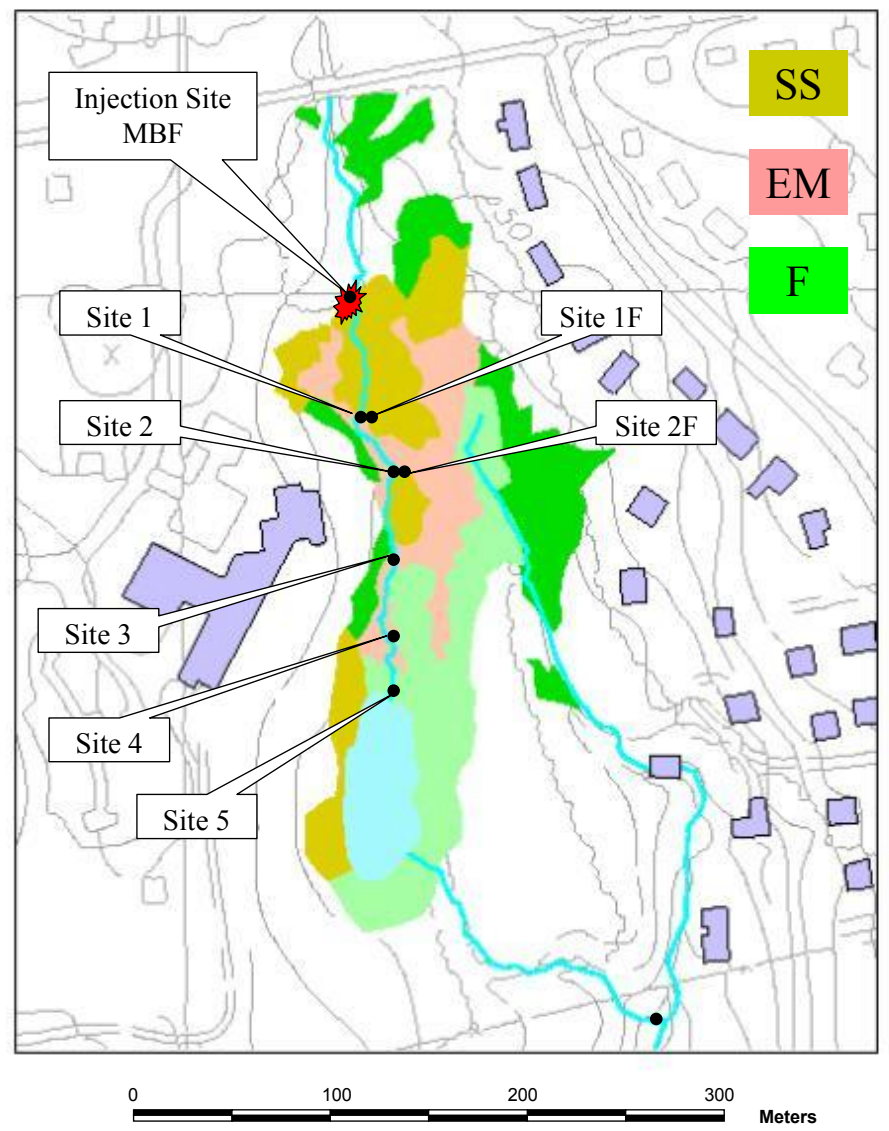

Figure 17.2 Map of delineated wetland segments and location of dye injection site and sampling stations. SS represents Scrub-Shrub type wetland, EM : emergent type wetland and F forested type wetland.

The Malcolm Brook watershed is primarily covered with a mix of lowdensity residential, commercial office and forested land uses. The entire watershed is sewered. It represents a typical watershed found in the suburbanized areas surrounding Kensico Reservoir.

Monitoring sites were located throughout the wetland within this watershed. Figure 17.2 provides the location of the sites along with the boundaries of the wetland segments. The upstream boundary identified as 
the Malcolm Brook Fork (MBF) site, is located just below where the flow splits and enters the western branch of Malcolm Brook. Downstream of $\mathrm{MBF}$, the sites were identified in numbered order from upstream to downstream as sites one through five. Two additional sites were located in the vegetated floodplain areas of site 1 and site 2 and identified as $1 \mathrm{~F}$ and $2 \mathrm{~F}$. A permanently gauged station (MB1) is located downstream of the location where the two branches of Malcolm Brook rejoin.

\subsection{Wetland Delineation and Segmentation}

Use of a standardized classification system to describe different wetland characteristics can reduce the variability associated with different sites or different individuals performing the delineation. Accordingly, this study segmented the wetland into polygons with the use of the US Fish and Wildlife's National Wetland Inventory (NWI) classification scheme (Cowardin et al 1979). The delineation of the wetland segments was accomplished by utilizing a Trimble model P20XR instrument to identify specific locations with Global Positioning System (GPS) technology. The accuracy of these measurements was approximately $\pm 1 \mathrm{~cm}$. Conventional surveying equipment was used to delineate the elevations and widths of the stream invert, stream bank and the extent of the flow in the vegetated floodplain. The GPS could not be used to collect this data due to its much lower accuracy in measuring elevations. The accuracy of the Trimble P20XR for elevations is approximately \pm 1 meter. The accuracy of surveying equipment was $\pm 0.3 \mathrm{~cm}$.

The GPS data were used in a Geographical Information System (GIS) to generate a map with the wetland class delineations and their corresponding geographical orientation (Figure 17.2). In addition to delineating the boundaries of each of the wetland types, the GPS was used to assist in the location of monitoring stations. The GIS system was also used to calculate channel and floodplain lengths, channel sinuosity, floodplain widths, and to associate the wetland "type" attribute to these features using GPS derived data. Segmentation of the stream corridor was based on the boundaries of the classified wetland areas. There was a consistent pattern within a wetland class of similar features that can affect flow. These included primarily the vegetation and its associated friction, and the sinuosity of the stream corridor found in the class. Segments classified as Emergent had relatively highly vegetated floodplains and contained stream segments with low sinuosity. 
Scrub-shrub classified segments had highly meandering streams with relatively scattered vegetation in its floodplains.

Table 17.1 Characteristics measured for each classified wetland segment.

\begin{tabular}{llll}
\hline Wetland Class & \multicolumn{1}{c}{$\begin{array}{c}\text { Scrub-Shrub } \\
(\mathrm{SS})\end{array}$} & $\begin{array}{c}\text { Emergent } \\
(\mathrm{EM})\end{array}$ & $\begin{array}{c}\text { Mixed } \\
(\mathrm{SS} / \mathrm{EM})\end{array}$ \\
\hline Area $\left(\mathrm{m}^{2}\right)$ & 1318.8 & 962.0 & 634.0 \\
Segment Length (m) & 71.83 & 32.24 & 37.58 \\
Average Segment Width (m) & 18.36 & 29.84 & 16.87 \\
Average Channel Width (m) & 1.37 & 0.78 & 0.79 \\
Stream Channel Length (m) & 367.14 & 125.98 & 154.15 \\
Channel Sinuosity & 1.56 & 1.19 & 1.25 \\
Relative Floodplain Vegetation Density & Low & High & Moderate \\
Floodplain Ave. Stem Dia. (cm) & & & \\
$\quad$ Leaf-off & 4.6 & 3.1 & 3.1 \\
$\quad$ Leaf-on & 3.4 & 0.9 & 3.7 \\
\hline
\end{tabular}

Table 17.1 provides a summary of several characteristics found with the wetland types that had observed surface flows. Wetland type, channel dimensions, floodplain vegetation density, and stem diameters were determined through field surveys. Average stem diameter was determined by measuring stems in randomly placed one-meter plots along a transect through a representative portion of the wetland segment. Stem diameter was measured at three elevations within the maximum flood flow level. The leaf-on season incorporated the time of year when the wetland vegetation reached its maximum density of leaf and stem growth while the leaf-off season was the time when the vegetation had the lowest density.

\subsection{Dye Tracer Test Methods}

Due to the diffuse nature of water entering and exiting natural wetlands, it is difficult to establish flow control structures to measure flows accurately. Accordingly, dye tracer tests provide the best method to determine the onedimensional average velocities associated with different combinations of wetland types. This was especially important due to the different velocities 
that exist between stream channel flow and floodplain flow. Although not reported here, the dye tracer tests also provided information on the dispersion properties of the flow through different wetland classes.

\subsubsection{Methods}

To conduct efficient dye studies and obtain the necessary approvals from the regulating authorities, comprehensive and detailed documents providing information on how the studies will be conducted is needed. Accordingly, both a Quality Assurance Plan (QAP) and a Standard Operating Procedure (SOP) document were produced based on the procedures presented in the American Society for Testing and Materials (ASTM), Annual Book of ASTM Standards, Section 11 Water and Environmental Technology (ASTM 1992) and the United States Geological Survey's Fluorometric Procedures for Dye Tracing (Wilson et al. 1986). The dye test program for wetlands consists of six major tasks:

1. determine which wetland segments to evaluate;

2. establish the level of flows or stages that are important to be tested;

3. measure the background fluorescence found in the stream prior to the introduction of tracer dye;

4. place dye at the upstream boundary of the wetland system;

5. collect water samples at timed intervals for each cross section of interest; and

6. analyze the water samples for the concentration of tracer dye.

The tracer dye selected for the study was a fluorescent organic compound known as Rhodamine WT ( $20 \%$ solution, Crompton \& Knowles Inc., Charlotte, N.C.). This dye is an excellent tracer because it is:

- water soluble;

- $\quad$ strongly fluorescent (therefore highly detectable at low concentrations);

- fluorescent in a part of the light spectrum not common to materials generally found in water;

- inexpensive;

- reasonably stable in a natural water environment; and

- $\quad$ relatively harmless in low concentrations (Wilson et al. 1986). 
Rhodamine WT is the only tracer material that is approved for use within water supply systems. It has also been the most common tracer used for measuring hydraulic properties of wetlands (Kadlec 2003; Shilton and Prasad 1996; Pilgrim et al 1992; Fisher 1990; Stairs and Moore 1994).

The initial dye concentration was determined in accordance with the dilution equations developed for large river system tracer tests (ASTM 1992). Higher concentrations were used in this study after initial monitoring for the tracer dye indicated that the tracer signal was too weak to be detected in the downstream sites. $50 \mathrm{ml}$ of stock solution of $20 \%$ concentrated Rhodamine WT dye was diluted into $1 \mathrm{~L}$ of de-ionized water to produce a diluted stock solution of ten- parts per thousand. 100-200 $\mathrm{ml}$ of this diluted stock dye solution was mixed with stream water to fill a $20 \mathrm{~L}$ plastic container equipped with a 12 volt pump (Shurflo model 2088-534-344). The pump was capable of delivering a flow of approximately $5 \mathrm{~L} / \mathrm{min}$ with one meter of head pressure. The entire volume of the dye tracer solution was injected into the stream channel at the upstream boundary of the wetland system at site MBF within one minute after the pump was energized.

Since flow through a wetland system is rather slow, it was necessary to use auto-sampling equipment to capture the dye tracer downstream over several hours. Accordingly, auto-samplers (Portable Sampler Model 3700, ISCO Corp.) were located at each downstream cross-section (monitoring sites 1 through 5 including the floodplain sites $1 \mathrm{~F}$ and $2 \mathrm{~F}$. The auto-samples were capable of collecting 24 1-L samples over a programmed period of time. Sample collection began shortly after the introduction of tracer dye to allow time for the auto-samplers to collect samples that reflected the background levels of fluorescence. The auto-samplers were initially programmed to collect a sample every fifteen minutes for the dye tracer tests performed under base flow conditions. The results from the initial tests performed during flood flow conditions indicated that the tracer curves could be captured with improved accuracy through five-minute sample intervals. This change was based on the magnitude of the decrease in travel time (hours to minutes) during storm events. As a result, the auto-samplers were programmed to collect a sample every five minutes.

A fluorometer (Model 10, Turner Corp., Sunnyvale, CA.) was used to measure the level of fluorescence in the water samples collected by the autosamplers. Measurement procedures followed those detailed in ASTM (1992), Wilson et al. (1986), and Turner Designs (1981). Also measured was temperature, turbidity (Hach turbiditimeter model 2100 Hach Co., Loveland, Co.) and particles in four ranges between 2 and 50 microns (Hach Log Easy 400 particle counter, Hach Co., Loveland, Co.). Results for each 
tracer test were recorded along with related information on a data form. This form included the fluorometer readings, their conversion into concentrations in parts per billion (ppb), temperature, and turbidity.

Time of travel was calculated by the difference in the times when the centroid of tracer dye mass passed from one site to the next. Average velocities for each wetland segment were calculated by dividing the length between monitoring stations by the time of travel.

\subsection{Results for Dye Tracer Tests}

Over a one-year period from September 1997 to October 1998, thirty-four dye tracer tests were performed during varying base and flood stages. Table 17. 2 provides an outline of the data collected for the tests. From the thirty-four tests, six tests failed to produce any data and seven tests failed to produce data at critical sites. These failures were due to equipment failure for either the auto-injection of dye tracer or the auto-samplers. A total of twenty-one tests produced results for both sites 1 and 2, which represented the sites of most interest. Of these tests, ten represented the leaf-on period (May 1 to October 15) and eleven represented the leaf-off season (October 16 to April 30). The results of the dye tracer tests produced the expected response curves for a non-ideal flow system.

Figure 17.3 provides a typical dye tracer response curve observed for the Malcolm Brook wetland system. The response observed at each monitoring site is represented by an asymmetric curve characterized by a right-skewed distribution. Decreasing peak concentrations were observed as the flow traveled further from the injection point. Minimal adsorption of dye was observed based on the relatively rapid return of dye concentrations to background levels. The greatest recovery of dye was observed at sites 1 and 2, which were closest to the injection point. Accordingly, this study focused on these sites, which also had the least variability. In addition, both these sites were nearly homogenous within their own wetland classification.

Figures 17.4 and 17.5 show typical response curves between base and flood flow conditions respectively at the sites representing the scrub-shrub segment (site 1 and site $1 \mathrm{~F}$ ) and the emergent segment (site 2 and site $2 \mathrm{~F}$ ). The same concentration of dye was injected during both tests although a larger volume of flow was present during flood flow conditions. The storm flow results $(6 / 12 / 98$ test) indicate that their response curves have sharper peaks and occur sooner than for the base flow results $(6 / 25 / 98$ test). The dye 
was not observed at the floodplain sites during base flow but was detected during flood flow. These results agree with field observations that indicated that during base flow conditions, the water was channelized and surface flow in the floodplains was observed only during flood flow conditions. It is important to note that this response was observed during the leaf-off season as well as the leaf-on season.

Table 17. 2. Summary of data collected for dye tracer tests.

\begin{tabular}{|c|c|c|c|}
\hline Date & Flow Type & Season & Sites with Dye Data \\
\hline $9 / 23 / 97$ & Base & Leaf-on & Missed Dye due to timing \\
\hline $10 / 2 / 97$ & Base & Leaf-on & 1 \\
\hline $10 / 8 / 97$ & Base & Leaf-on & $3,4,5$ \\
\hline $10 / 16 / 9$ & Base & Leaf-off & $1,2,3,4,5$ \\
\hline $10 / 27 / 9$ & Base & Leaf-off & $2,3,4,5$ \\
\hline $10 / 31 / 9$ & Base & Leaf-off & $1,2,3,4,5$ \\
\hline $11 / 6 / 97$ & Base & Leaf-off & $1,2,3,4,5$ \\
\hline $11 / 20 / 9$ & Base & Leaf-off & $1,2,3,4,5$ \\
\hline $12 / 1 / 97$ & Base & Leaf-off & $1,2,3,4,5$ \\
\hline $12 / 3 / 97$ & Base & Leaf-off & $1,1 \mathrm{~F}, 2,2 \mathrm{~F}, 3,4,5$ \\
\hline $12 / 5 / 97$ & Base & Leaf-off & $1,1 \mathrm{~F}, 2,3,5$ \\
\hline $12 / 12 / 9$ & Base & Leaf-off & $1,1 \mathrm{~F}, 2,2 \mathrm{~F}, 3,4,5$ \\
\hline $12 / 18 / 9$ & Base & Leaf-off & $1,1 \mathrm{~F}, 2,2 \mathrm{~F}, 3,4,5$ \\
\hline $1 / 29 / 98$ & Base & Leaf-off & $1,1 \mathrm{~F}, 2,2 \mathrm{~F}, 3,4,5$ \\
\hline $3 / 9 / 98$ & Storm & Leaf-off & $1,1 \mathrm{~F}, 2 \mathrm{~F}, 3,4,5$ \\
\hline $3 / 19 / 98$ & Storm & Leaf-off & $1,1 \mathrm{~F}, 2,3,4,5$ \\
\hline $4 / 7 / 98$ & Base & Leaf-off & 1 \\
\hline $5 / 6 / 98$ & Base & Leaf-on & $1,2,3,4$ \\
\hline $5 / 7 / 98$ & Storm & Leaf-on & $2,2 \mathrm{~F}$ \\
\hline $6 / 5 / 98$ & Base & Leaf-on & $1,2,3,4,5$ \\
\hline $6 / 12 / 98$ & Storm & Leaf-on & $1,1 \mathrm{~F}, 2,2 \mathrm{~F}, 3,4,5$ \\
\hline $6 / 25 / 98$ & Base & Leaf-on & $1,2,3,4,5, \mathrm{mb} 3$ \\
\hline $7 / 1 / 98$ & Base & Leaf-on & $1,2,3,4,5$ \\
\hline $7 / 17 / 98$ & Base & Leaf-on & $1,2,3,4$ \\
\hline $7 / 23 / 98$ & Storm & Leaf-on & Failed auto-dye injection \\
\hline $7 / 30 / 98$ & Storm & Leaf-on & Failed auto-dye injection \\
\hline $8 / 4 / 98$ & Base & Leaf-on & Failed auto-dye injection \\
\hline $8 / 13 / 98$ & Base & Leaf-on & $1,2,3,4$ \\
\hline $8 / 18 / 98$ & Storm & Leaf-on & Failed auto-dye injection \\
\hline $8 / 26 / 98$ & Storm & Leaf-on & $1,1 \mathrm{~F}, 2,2 \mathrm{~F}, 3,4$ \\
\hline $8 / 28 / 98$ & Storm & Leaf-on & Failed auto-dye injection \\
\hline $9 / 2 / 98$ & Storm & Leaf-on & $1,2 \mathrm{~F}$ \\
\hline $10 / 1 / 98$ & Base & Leaf-on & $1,2,3,4$ \\
\hline $10 / 8 / 98$ & Storm & Leaf-on & $1,1 \mathrm{~F}, 2,2 \mathrm{~F}, 3,4$ \\
\hline
\end{tabular}




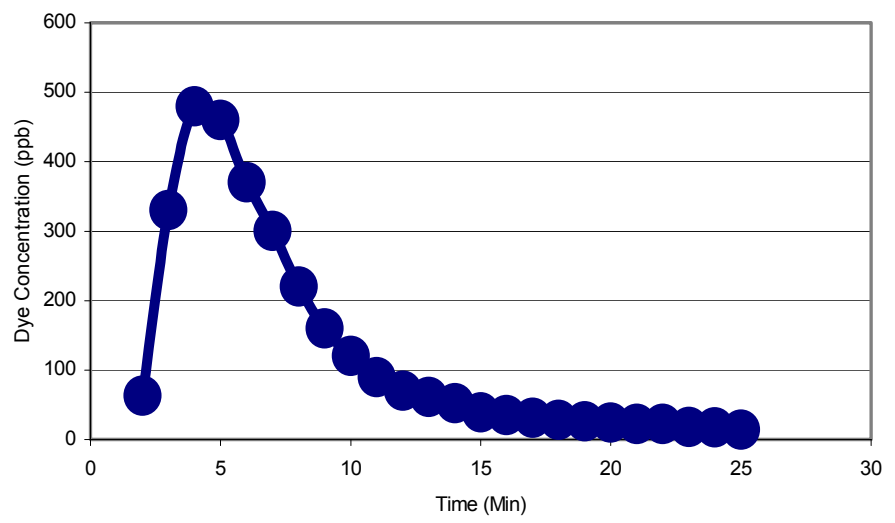

Figure 17.3 Typical dye tracer response curve.

Malcolm Brook Wetland Under Baseflow Conditions

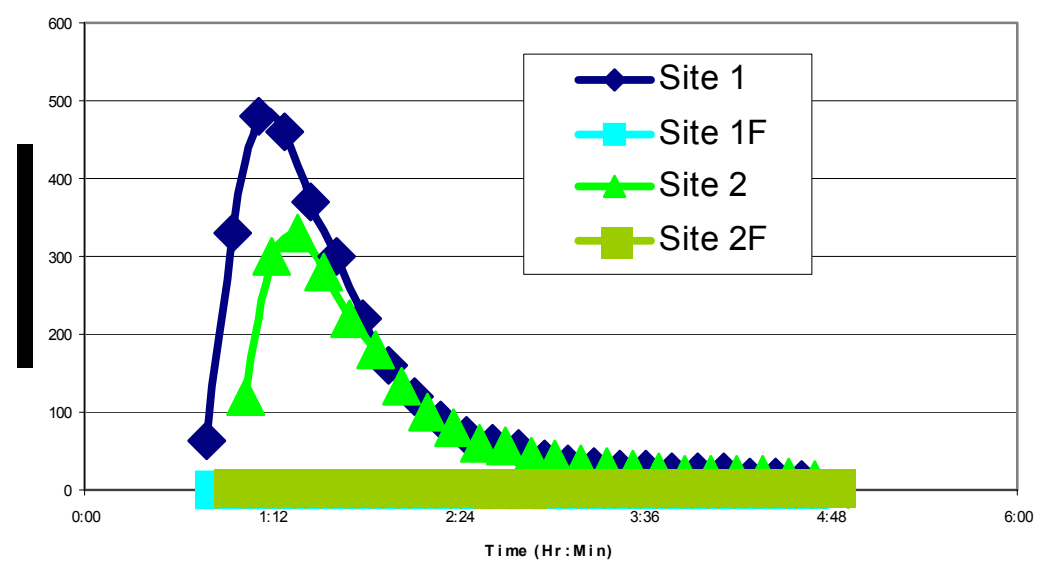

Figure 17.4 Dye tracer response curves under baseflow conditions.

Increasing scatter was observed for sites furthest from the injection point. Explanations for this scatter include increased fluorometer variability for samples with lower concentrations and increased dispersive flow paths as the tracer dye moved from one wetland segment to the next. The least 
scatter was observed at sites 1 and 2, which were closest to the tracer dye injection. Therefore, evaluation of the velocity differences between wetland types was based on the less variable data associated with these two sites.

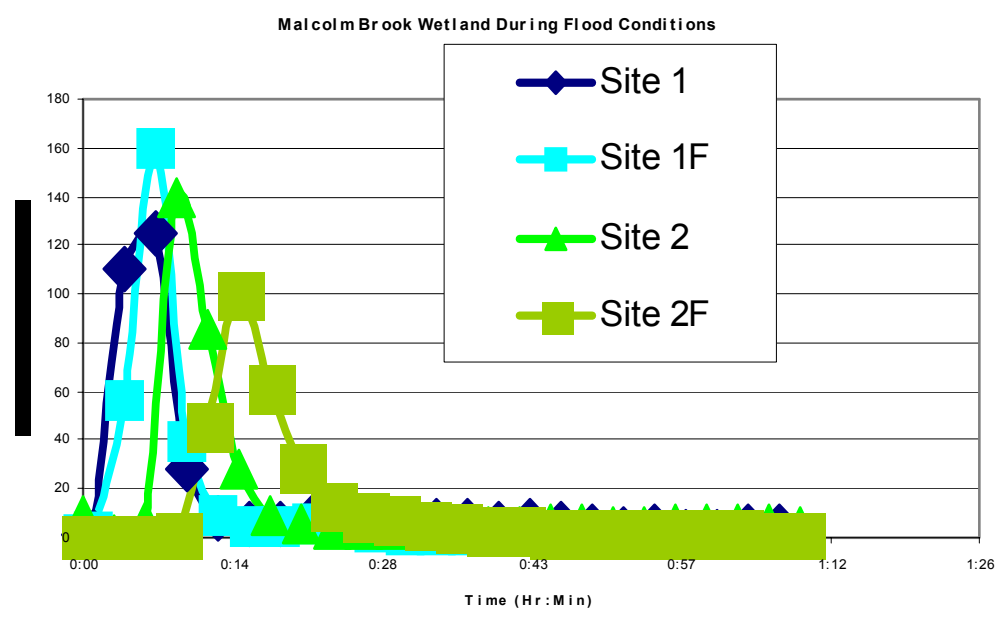

Figure 17.5 Dye tracer response curves under flood flow conditions.

Data obtained from the twenty-one successful tracer tests was used to calculate average flow velocities. The velocities associated with each wetland classification were compared to determine the behavior of the flow in each classified segment under a range of flow conditions.

Figures 17.6 and 17.7 provide a comparison in velocities during different stages of flow for the two predominant types of wetlands during the leaf-on and leaf-off seasons respectively. Site 1 represents the flow through the scrub-shrub type wetland whereas site 2 represents the flow through the emergent type. The range of velocities observed for scrub-shrub classified segment was from 1.13 to $24.82 \mathrm{~m} / \mathrm{min}$ during the leaf-on season and from 0.48 to $12.16 \mathrm{~m} / \mathrm{min}$ during the leaf-off season. For the emergent classified segment, the range of velocities was from 1.35 to $6.70 \mathrm{~m} / \mathrm{min}$ during the leaf-on season and from 0.42 to $8.22 \mathrm{~m} / \mathrm{min}$ during the leaf-off season.

During the leaf-on season, the scrub-shrub type wetland exhibited approximately $20 \%$ lower flow velocities than the emergent type wetland during base flow conditions (Figure 17.6). However, during flood flow conditions, the scrub-shrub type wetland had approximately $70 \%$ greater 
flow velocities than the emergent type. For the leaf-off season, the scrubshrub type wetland exhibited approximately $2 \%$ lower flow velocities (on average) than the emergent type wetland during base flow conditions (Figure 17.7). However, during flood flow conditions, the scrub-shrub type wetland had approximately $3 \%$ greater flow velocities than the emergent type.

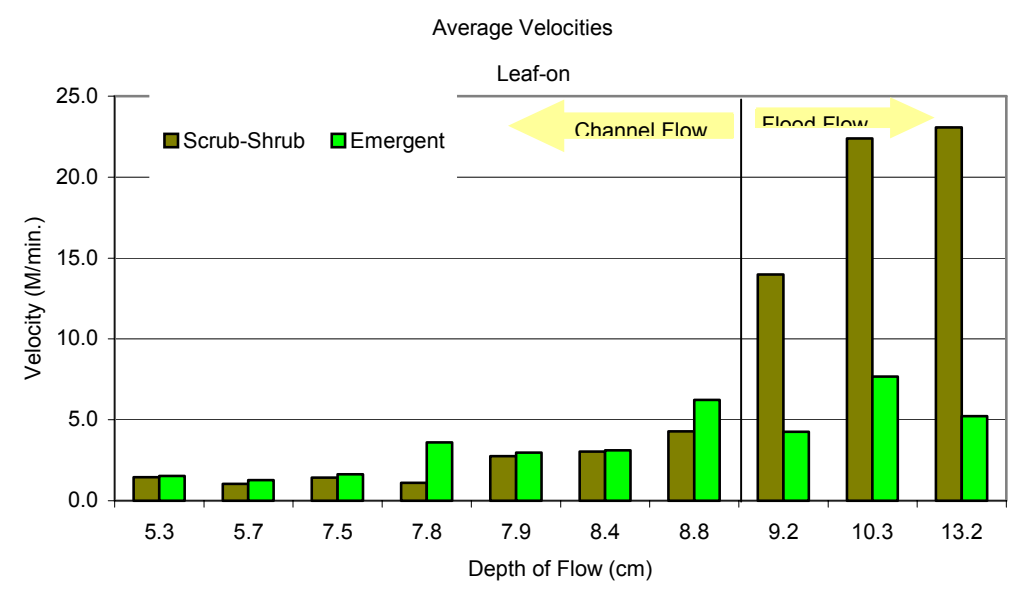

Figure 17.6 Average velocity of dye compared with flow depth as the dye travels through two types of wetlands during leave-on season.

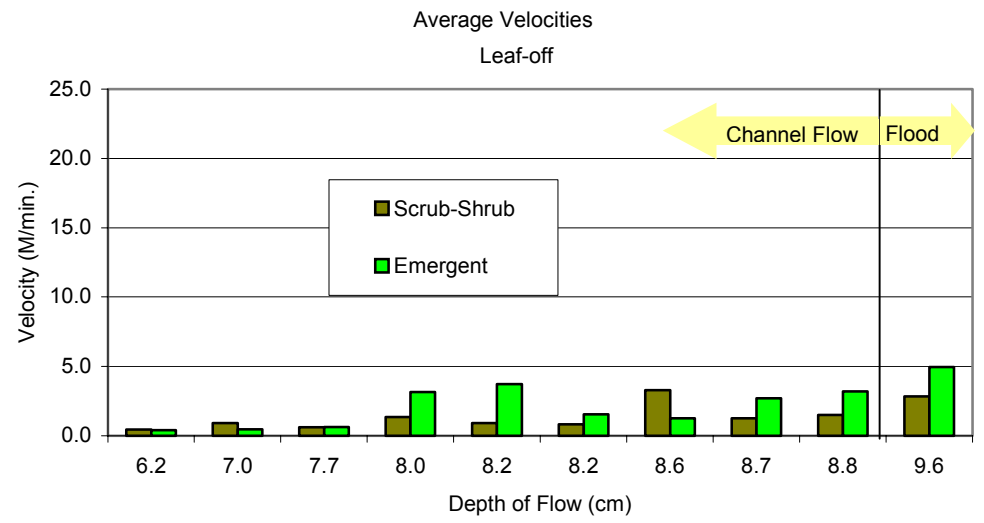

Figure 17.7 Average velocity of dye compared with flow depth as the dye travels through two types of wetlands during leave-off season. 
Figure 17.7 indicates a noticeable decrease in velocities observed during the leaf-off season. Averaged together, the leaf-on velocity for all the dye tracer tests was $8.02 \mathrm{~m} / \mathrm{min}$ for the scrub-shrub type wetland and $4.03 \mathrm{~m} / \mathrm{min}$ for the emergent type wetland. During the leaf-off period these values decreased to $2.47 \mathrm{~m} / \mathrm{min}$ for the scrub-shrub type wetland and $2.90 \mathrm{~m} / \mathrm{min}$ for the emergent type wetland. The more dramatic decrease for the scrubshrub type wetland was most reflected in the flood flow conditions.

\subsection{Discussion}

The successful capture of dye along with the reproducibility of the results indicated that the test methods used in this study were adequate in describing flow through natural wetlands. The use of Rhodamine WT as the tracer material adequately delineated the movement of water through the natural wetlands. The results did not indicate significant adsorption of this dye tracer. The dye tracer signal measured at the downstream monitoring stations indicated similar patterns under comparable flow velocities. Part of this consistency can be attributed to the riverine nature of the wetland system studied. During base flow conditions, the presence of the stream channel directed the flow to travel in a well-defined path. Without the channel, the flow could travel through several paths depending on only slight modifications of the micro-channels commonly found in wetlands. Accordingly, the methods used in this study are not adequate for wetland systems that are stagnant or exhibit multidirectional flow such as those that are found in the headwaters of a watershed. In these wetlands, flow needs to be described in at least two dimensions.

The results also support the use of the USFWS NWI classification scheme as a method to distinguish the hydraulic properties associated with different types of natural wetlands. Although this classification scheme was developed primarily for the purpose of inventorying wetlands found in the United States to support regulatory management (Cowardin, et al 1979), its dependence on vegetation for classification allows it to be applicable to hydraulic features as well. One explanation for this applicability of the USFWS NWI classification scheme is that the presence of particular wetland vegetation is a reflection of the hydrology of the area it inhabits. 

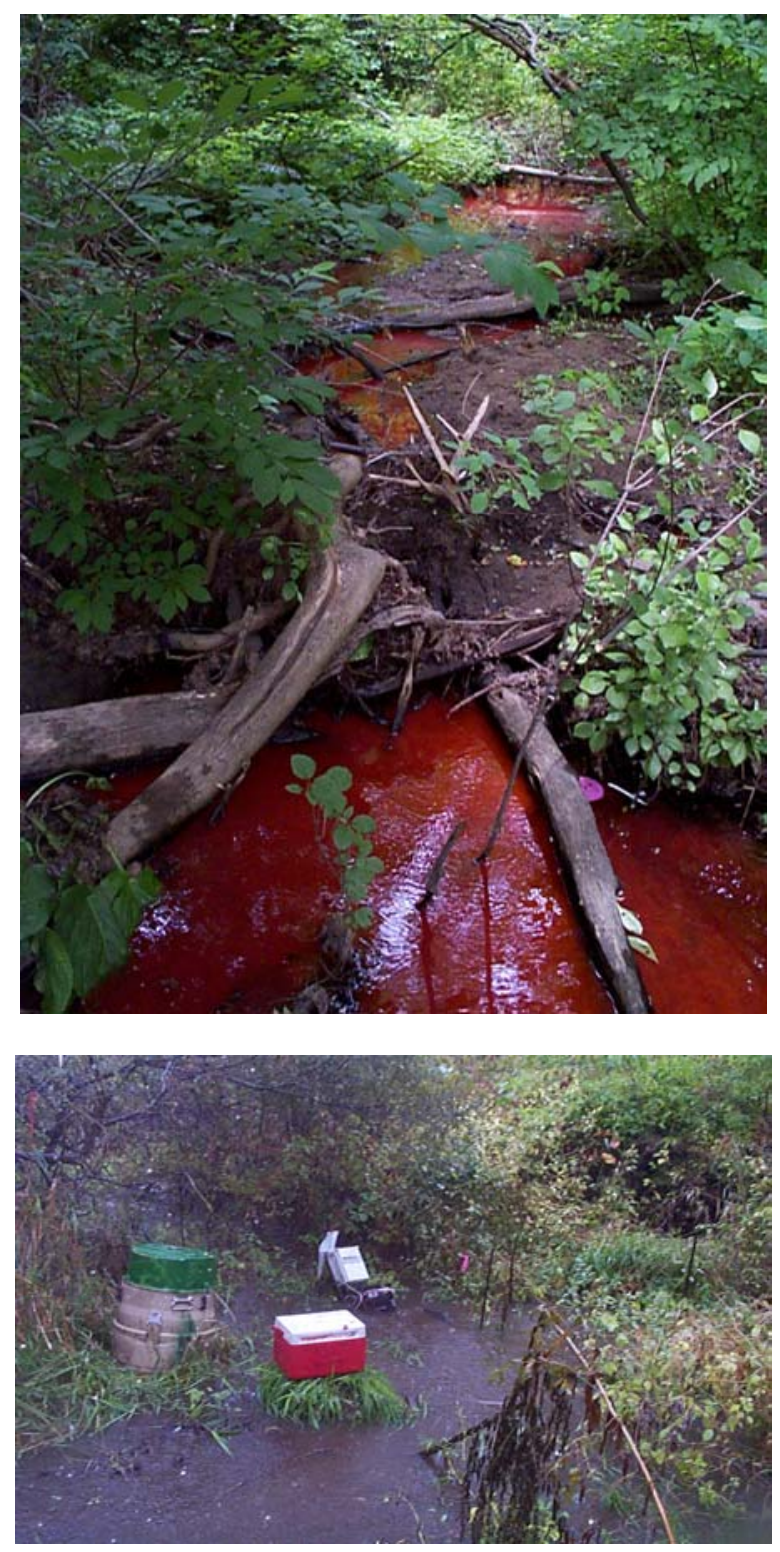

Figure 17.8 Flow pattern during base flow condition (a) and flood flow condition (b) illustrating reduction in meandering. 
Unfortunately, this study was only able to evaluate two classifications within one wetland system. Additional studies are needed to determine the hydraulic characteristics of different classifications and to determine the variability of the hydraulic properties within each classification. This can be best accomplished through additional dye tracer studies at a range of natural wetland sites at different locations. Such studies are now planned for a wetland system located in Wayne, New Jersey. The wetland to be studied is located in a suburbanized watershed similar to Malcolm Brook. It is composed of mostly scrub-shrub and forested wetland segments.

In addition to the changes in the hydraulic features observed between different classified wetland segments, there were measurable differences in average velocities between base and flood flow conditions. In this context, two wetland characteristics appear to have a profound effect on the flow velocity, stream sinuosity and vegetation density. The combined effect of these two characteristics resulted in the velocity pattern presented in Figures 17.6 and 17.7. The sinuosity of the stream significantly affects the length of the flow path and therefore the average flow velocity through a segment. During base flow conditions, most of the flow is channelized within the stream corridor of the wetland segments. Since the stream channel in the scrub-shrub type wetland exhibited a higher level of sinuosity, the average flow velocity was lower relative to the emergent type wetland. As the flow increased during a storm event it began to overtop the banks of the channel. Within the scrub-shrub type wetland, the overtopping significantly shortened the distance the flow must travel to transverse the segment (Figures 17.8a and $17.8 \mathrm{~b}$ ). Instead of following the meandering stream channel, the portion of flow above the channel banks traveled in a straight path through the wetland's floodplain. The greater sinuosity observed within the scrub-shrub type wetland was due to the vegetative features found with this classification. The woody roots and stems of the vegetation found in scrubshrub type wetlands act as semi-permanent obstructions in the flow path of the stream channel. These obstructions aid in the development of meanders.

\subsection{Summary and Conclusions}

Since wetlands can have a positive influence on water quality, there has been a growing interest in developing models that can simulate the flow and water quality changes that occur when stream flow travels through these systems. This study represents a first attempt to evaluate the hydraulic behavior of 
natural wetlands. Published studies on wetland flow have focused almost exclusively on constructed wetlands. Study of the hydraulics of natural wetlands has been limited because natural wetlands are irregularly shaped, can be composed of heterogenous vegetation and tend to include meandering stream channels. These features cause the flow characteristics associated with natural wetlands to be more dynamic than those for constructed wetlands.

The findings presented here have been used to develop a hydraulic wetland model that explicitly accounts for the occurrence of meandering streams, vegetation density, and friction (Stern 2001a, Stern 2005a, Stern 2005b). These features influence wetland retention times which in turn affect pollutant fate and transport. The overall goal of the development of this model was to provide an improved description of flow through a natural wetland that is based on variables that can be measured in the field without extraordinary resources. A considerable amount of field data were collected and analyzed to describe the hydraulics of natural wetlands and provide a basis for the theory of the model. This information also enabled the model to be calibrated and verified.

Dye tracer tests were used in this study to develop a description for the hydraulics of different wetland types during different seasons. This description included the influence of different classified wetland segments on average velocities between base and flood flow conditions. Through dye tracer studies of two types of wetlands (scrub-shrub and emergent), two wetland characteristics were found to have a profound effect on the flow: stream sinuosity and vegetation density.

In addition to the changes in the hydraulic features observed between different classified wetland segments, there were differences in average velocities between the leaf-on and leaf-off seasons. Generally, the dye tracer tests indicated that velocity is slower during the leaf-off season. This finding was also predicted through the modeling results. While counterintuitive, this finding may be explained by the fact that flow through a natural wetland is generally shallow and during the leaf-off period there is a greater amount of leaf litter in the zone of flow.

This study found that the scrub-shrub wetlands act hydraulically similar to a shallow detention basin where flow is detained during base flow conditions then released more rapidly during flood flow conditions. Emergent wetlands appear to have a reverse effect. During low flows an emergent wetland behaves hydraulically similar to an open channel and at high flows it behaves similar to a retention tank with a large storage capacity during high flows. The arrangement of wetland types observed in Malcolm 
Brook may be ideal for controlling pollution from the first wash-off of a storm. In Malcolm Brook, the first flush is detained mostly by scrub-shrub wetlands whereas the peak flow is retarded by the emergent wetland.

In conclusion, improving our understanding of how natural wetlands modify flow through a watershed can lead to improvements in water resources management. Characterizing the hydrodynamic function of natural wetlands can lead to improvements to water quality remediation and provide justification for wetland creation. Such optimization could result in the replacement of concrete and steel structures with wetlands composed of different types of wetlands in order to provide water quality and quantity improvements.

\section{References}

ASTM (American Society for Testing and Materials), 1992. "Method D 561394:Standard Test Method for Open-Channel Measurement of Time of Travel Using Dye Tracers." In: ASTM (American Society for Testing and Materials), Annual Book of ASTM Standards, Section 11 Water and Environmental Technology. ASTM, Philadelphia, Pa., p. 736-45.

Cowardin, L.M., V. Carter, F.C. Golet and E.T. LaRoe, 1979. Classification of Wetlands and Deepwater Habitats of the United States. U.S. Fish and Wildlife Service Biological Services Program Report FWS/OBS - 79/31., Washington, DC. pp.103.

Elder, J.F., 1987. "Indicator Bacteria Concentrations as Affected by Hydrologic Variables in the Apalachicola River, Florida." Water, Air, and Soil Pollution WAPLAC 32(3):407-16.

Fisher, P.J., 1990. "Hydraulic Characteristics of Constructed Wetlands at Richmond. NSW, Australia." In:. Constructed Wetlands in Water Pollution Control. P.F.Cooper, B.C.Findlater, editors Oxford, U.K.:Pergamon Press. p 21-31.

Johnston, C.A., T. Johnson, M. Kuehl, D. Taylor, and J Westman, 1990. The Effects of Freshwater Wetlands on Water Quality: Compilation of Literature Values. USEPA, Corvallis Research Laboratory, Corvallis, OR. 178 pp.

Kadlec, R.H., 2003. Effects of Pollutant Speciation in treatment Wetlands Design. Ecological Engineering. Volume 20, Issue 1, Pp $1-16$.

Kadlec, R.H. and R.L. Knight, 1996. Treatment Wetlands. Lewis Publishers, Boca Raton, FL. 848 pp.

Mitsch, W.J. and J.G. Gosselink, 1993. Wetlands. Second edition. Van Nostrand Reinhold. New York. 722 pp.

Pilgrim, D.J., T.J. Schulz, and I.D. Pilgrim, 1992. "Tracer Investigation of Flow Patterns in Two Field Scale Constructed Wetlands with Subsurface Flow". Proceedings of 3rd International Conference on Wetland Systems for Water Pollution Control. Sydney, Australia. 
Schueler, T.R., 1992. Design of Stormwater Wetland Systems: Guidelines for Creating Diverse and Effective Wetlands in the Mid-Atlantic Region. Washington, D.C.: Metropolitan Washington Council of Governments.

Shilton, A.N., and J.N. Prasad, 1996. "Tracer Studies of a Gravel Bed Wetland". Wat.Sci.Tech. 34(3-4):421-5.

Stairs, D.B. and J.A. Moore, 1994. "Flow Characteristics of Constructed Wetlands: Tracer Studies of the Hydraulic Regime". In: Proceedings of 4th International Conference on Wetland Systems for Water Pollution Control. Guangzhou, China.

Stern, D.A., 2006. Modeling Flow through Natural Wetlands with a Modified Dynamic Wave Equation. Journal of Hydraulic Engineering. Submitted

Stern, D.A., 2001. Modeling Flow Through Natural Wetlands with a Modified Dynamic Wave Equation, CUNY Graduate Center, New York, NY

Stern, D.A., L.L. Janus, R. Khanbilvardi, J.C. Alair, W.R. Richardson, P.B. McCann, and Y.A. Gorokhovich, 1998. "Estimating Flow Velocities through a Natural

Stern, D.A., R. Khanbilvardi, J. Alair, and W. Richardson, 2001. Description of Flow Through a Natural Wetland Using Dye Tracer Tests. Ecological Engineering. Volume 18, Issue 2, Pp 173 - 184

Wetland." In: Water resources Engineering '98, Proceedings of the International Water Resources Engineering Conference. August 1998. ASCE, Reston, Va. p 502-507

Turner Designs Inc., 1981. Model 10 Operational Manual. Turner Designs Inc. Sunnyvale, CA. 35 pp.

U.S. Environmental Protection Agency, 1985. Freshwater Wetlands for Wastewater Management, Environmental Assessment Handbook. Atlanta, GA.: EPA Region IV. EPA-904/9-85-135.

Wilson, J.F., E.D.Cobb, F.A.Kilpatrick, 1986. Fluorometric Procedures for Dye Tracing. U.S. Geological Survey Denver, CO . 